\title{
3 begell
}

Begell House, Inc. Publishers

Journal Production

50 Cross Highway

Redding, CT 06896

Phone: 1-203-938-1300

Fax: 1-203-938-1304

Begell House Production Contact : journals@begellhouse.com

Dear Corresponding Author,

Attached is the corresponding author pdf file of your article that has been published.

Please note that the pdf file provided is for your own personal use and is not to be posted on any websites or distributed in any manner (electronic or print). Please follow all guidelines provided in the copyright agreement that was signed and included with your original manuscript files.

Any questions or concerns pertaining to this matter should be addressed to journals@begellhouse.com

Thank you for your contribution to our journal and we look forward to working with you again in the future.

Sincerely,

Michelle Amoroso

Michelle Amoroso

Production Department 


\title{
In Vitro Antitumor Effects of the Cold-Water Extracts of Mediterranean Species of Genus Pleurotus (Higher Basidiomycetes) on Human Colon Cancer Cells
}

\author{
Simona Fontana, ${ }^{1, *}$ Anna Flugy, ${ }^{1}$ Odessa Schillaci, ${ }^{1}$ Alessandra Cannizzaro, ${ }^{1}$ Maria Letizia \\ Gargano, ${ }^{2}$ Alessandro Saitta, ${ }^{2}$ Giacomo De Leo, ${ }^{1}$ Giuseppe Venturella, ${ }^{2}$ \& Riccardo Alessandro ${ }^{1}$ \\ ${ }^{1}$ Department of Biopathology and Medical and Forensic Methodologies, Università di Palermo, Palermo, Italy.; \\ ${ }^{2}$ Department of Agricultural and Forest Sciences, Università di Palermo, Palermo, Italy \\ *Address all correspondence to: Simona Fontana, Department of Biopathology and Medical and Forensic Methodologies, Università di Palermo, \\ via Divisi, 83 - 90133 Palermo, Italy; Tel.: +39 0916554604; Fax: +39 0916554624; simona.fontana@unipa.it.
}

\begin{abstract}
The aim of this study was to evaluate whether the cold-water extracts of Pleurotus eryngii var. ferulae (CWE-Pef) and Pleurotus nebrodensis (CWE-Pn), 2 of the most prized wild and cultivated edible mushrooms, can affect the tumor phenotype of human colon cancer HCT116 cells. Our results showed that treatment with CWEPef and CWE-Pn resulted in a significant inhibition of the viability of HCT116 cells and promoted apoptosis, as also demonstrated by the increase of $B a x$-to- $B c l-2$ messenger RNA ratio. Moreover, we observed that both extracts were able to inhibit cell migration and to affect homotypic and heterotypic cell-cell adhesion. It also was found that treatment with CWE-Pef and CWE-Pn negatively modulated the phosphorylation of the protein tyrosine as well as the phosphorylation levels of extracellular signal-regulated kinase $1 / 2$. In conclusion, the in vitro antitumor effects of CWE-Pef and CWE-Pn indicate that they can be considered as possible sources for new alternative therapeutic agents for cancer treatment.
\end{abstract}

KEY WORDS: medicinal mushrooms, Pleurotus eryngii var. ferulae, Pleurotus nebrodensis, human colon cancer, antitumor activity

\begin{abstract}
ABBREVIATIONS: CWE-Pef, cold-water extract from Pleurotus eryngii var. ferulae; CWE-Pn, cold-water extract from Pleurotus nebrodensis; DMSO, dimethyl sulfoxide; HUVEC, human umbilical cord endothelial cell; mRNA, messenger RNA; PCR, polymerase chain reaction.
\end{abstract}

\section{INTRODUCTION}

Colorectal cancer is the third most commonly diagnosed cancer in males and the second in females. Almost $50 \%$ of patients diagnosed with colorectal cancer die because of the disease and only less than $10 \%$ of patients with metastatic cancer survive more than 5 years after their diagnosis. ${ }^{1}$ Although some patients with early-stage colon cancer can be cured by surgical resection alone, usually the treatment of both early and advanced colorectal cancers is based on a multimodal approach in which surgery is combined with adjuvant radio- and chemotherapy. ${ }^{2}$ However, the severe side effects of these therapies too often supersede their benefits and worsen patients' quality of life. For this reason, the discovery of new, safer, and more effective therapeutic agents is needed to better treat colon cancer.

Mushrooms have been used for centuries as folk medicines, especially in Asian countries, where their medicinal properties are well known. Because of the great quantity of experimental evidence collected in the past two decades, the immunomodulatory and antineoplastic properties of substances extracted from various species of edible mushrooms are now also extensively recognized at a scientific level. ${ }^{3}$ The most promising biologically active compounds obtained from mushrooms are polysaccharides, ${ }^{4-7}$ polysaccharide-protein complexes, ${ }^{8,9}$ proteins, ${ }^{10-12}$ and triterpenes. ${ }^{13-15}$ Several published works have demonstrated that the anticancer properties of these molecules is due to their ability to en- 
Fontana et al.

hance immune system activity and/or act directly on cancer cells. ${ }^{3-5,9,11,15,16}$ Some of the most studied medicinal mushrooms are those belonging to the genus Pleurotus (Fr.) P. Kumm., which includes widely cultivated edible mushrooms., ${ }^{3,17}$ Most of the research concerning the antitumor properties of Pleurotus spp. have been carried out by testing the methanol/ethanol/hot water extracts of $P$. ostreatus (Jacq.:Fr.) P. Kumm. in several in vivo and in vitro cancer models. ${ }^{3,17-23}$ These studies have provided interesting data supporting the possibility of isolating new therapeutic agents from this mushroom, but much less is known about the biological activities of extracts from other Pleurotus species.

Pleurotus eryngii (DC.:Fr.) Quél. var. ferulae (Lanzi) Sacc. and P. nebrodensis (Inzenga) Quél. are typical Mediterranean mushroom species and are particularly popular as choice edible mushrooms. $P$. eryngii var. ferulae is abundantly collected from calcareous soils in garigues, wastelands, and arid pastures from September to mid-June, from sea level to an elevation of approximately $1000 \mathrm{~m} . P$. nebrodensis is a rare and declining mushroom with a fructification period restricted from mid-April to mid-June. It grows in arid pastures in calcareous soils at elevations of 1200 to $2000 \mathrm{~m}^{24}$

Isozyme and random amplification of polymorphic DNA polymerase chain reaction (PCR) analyses have confirmed that $P$. eryngii var. ferulae and $P$. nebrodensis are clearly genetically different. ${ }^{25}$ As reported by La Guardia et al. ${ }^{26}$ the wild and cultivated $P$. eryngii var. ferulae and $P$. nebrodensis mushrooms are suitable in every type of diet, including hypocaloric diets, thanks to their low caloric content and gastronomic value. In addition, these mushrooms are a good source of vitamins and mineral salts.

The aim of this study was to evaluate whether the cold-water extracts of $P$. eryngii var. ferulae (CWE-Pef) and P. nebrodensis (CWE-Pn) can affect the tumor phenotype of human colon cancer cells. We found that CWE-Pef and CWE-Pn inhibited the growth of HCT116 colon cancer cells by inducing apoptosis, promoted cancer cell aggregation, and inhibited cell migration and the adhesion of tumor cells to endothelial cells. These effects were specific for tumor cells; no effects were observed on nontumor cells.

\section{MATERIALS AND METHODS}

\section{A. Mushroom Extracts}

The mushroom samples were cleaned of debris with a knife, cut into pieces and placed in plastic bags for freezing, then transported to a laboratory and frozen at $-80^{\circ} \mathrm{C}$. Every sample contained complete mushroom basidiomata (cap, gills, and stipe). The mushrooms were identified according to macro- and micromorphological descriptions reported by previous studies. ${ }^{24,27}$ The original material of mushroom basidiomata is kept in the Laboratory of Mycology at the Department of Agricultural and Forest Science, University of Palermo.

Finally, the frozen mushrooms were lyophilized. According to internal quality control procedures for the collection and treatment of plant materials, contaminated samples (by soil, dust, etc.) were washed in tap water for a few seconds. The lyophilized sample $(3 \mathrm{~g})$ was placed in a beaker with $200 \mathrm{~mL}$ of demineralized water, frozen, and then placed in a refrigerator at $-20^{\circ} \mathrm{C}$. The sample was subsequently filtered within a $250-\mathrm{mL}$ balloon, lyophilized to remove any water, weighed and redissolved in $10 \%$ dimethyl sulfoxide (DMSO) at a concentration of $500 \mathrm{mg} / \mathrm{mL}$ (stock solution). From each stock solution of CWE-Pef and CWE$\mathrm{Pn}$, a working solution of $5 \mathrm{mg} / \mathrm{mL}$ in McCoy's 5A modified medium (sterilized with a sterile filter with a $0.22-\mu \mathrm{m}$ pore size; Millipore, Inc., Billerica, MA) was prepared and used for all experimental procedures. The maximum dose of mushroom extract used in the assays was $100 \mu \mathrm{g} / \mathrm{mL}$ containing $0.002 \%$ DMSO. Mushroom extract was added to HCT-116 cells 18 hours after seeding.

\section{B. Cell Culture}

The human colon carcinoma cell line HCT-116 was cultured in McCoy's 5A modified medium plus $10 \%(\mathrm{v} / \mathrm{v})$ dialyzed heat-inactivated fetal bovine serum, $100 \mathrm{U} / \mathrm{mL}$ penicillin, and $100 \mu \mathrm{g} / \mathrm{mL}$ 
streptomycin at $37^{\circ} \mathrm{C}$ in a humidified atmosphere of $95 \%$ air and $5 \%$ carbon dioxide. Human umbilical cord endothelial cells (HUVECs) were obtained from Lonza (Clonetics, Verviers, Belgium) and grown in endothelial growth medium according to the manufacturer's indications.

\section{Cell Survival Assay}

Cell viability was assessed by crystal nuclear staining. ${ }^{28}$ In brief, HCT-116 cells and HUVECs were seeded in media at respective concentrations of $2.5 \times 10^{4}$ and $1.5 \times 10^{4}$ cells $/ \mathrm{cm}^{2}$ in 96 - or 24 -well plates. After 18 hours, the cells were washed and treated for 24 hours with DMSO (used as a control) and with different concentrations of either CWEPef or CWE-Pn $(10,20,50$, and $100 \mu \mathrm{g} / \mathrm{mL})$. At the end of the treatment, the culture medium was carefully removed and washed twice with complete phosphate-buffered saline; then a solution of $0.5 \%$ crystal violet in $20 \%$ methanol was added to each well and kept for 10 minutes at room temperature. Finally, the plate was washed, drained, and the stain was solubilized by adding a $1: 1(\mathrm{v} / \mathrm{V})$ solution of $0.1 \mathrm{M}$ sodium citrate $(\mathrm{pH} 4.2) / 100 \%$ ethanol at room temperature for 20-30 minutes with agitation. The plate was read at $540 \mathrm{~nm}$ with a microtiter plate reader. The rate of cell growth inhibition was calculated, taking into account the average results obtained from at least 3 independent experiments by calculating the percentage of growth in relation to the control with the following formula: (optical density of the treated cells/optical density of the control group) $\times 100$.

\section{Apoptosis Assays}

HCT-116 cells were treated with 5, 10, 15, and 20 $\mu \mathrm{g} / \mathrm{mL}$ of CWE-Pef or CWE-Pn and with DMSO as the control. After 18 hours of culture, cells were harvested, collected, washed, and stained with acridine orange/ethidium bromide, according to the method described by Saydam et al..$^{29}$ This staining, combined with fluorescent microscopy, was used to distinguish viable from apoptotic cells. ${ }^{30} \mathrm{At}$ least 200 cells/field were counted in each experi- ment. The histograms in figure 3A show, for each condition, the percentage of apoptotic cells, which was calculated as follows: ([no. of early apoptotic cells + no. of late apoptotic cells]/total no. of cells) $\times 100$. The values reported in these graphs are the average results obtained from at least 3 independent experiments.

\section{E. RNA Extraction and Real-Time PCR}

HCT-116 cells were treated for 18 hours with different concentrations $(10,20$, and $50 \mu \mathrm{g} / \mathrm{mL})$ of either CWE-Pef or CWE-Pn and with DMSO as the control. RNA was extracted using the commercially available Illustra RNAspin Mini Isolation Kit (GE Healthcare, Little Chalfont, Buckinghamshire, UK), according to the manufacturer's instructions. Total RNA was reverse-transcribed to complementary DNA using the High Capacity cDNA Reverse Transcription Kit (Applied Biosystem, Foster City, CA, USA). Real time-PCR was performed in 48-well plates using the Step-One Real-Time PCR system (Applied Biosystems, Foster City, CA, USA).

Bax transcription levels were measured by performing a quantitative Sybergreen real-time PCR, which was carried out in a total volume of $20 \mu \mathrm{L}$ containing $2 \times$ SYBR Green I Master Mix (Applied Biosystems), $2 \mu \mathrm{L}$ complementary DNA, and 300 $\mathrm{nM}$ forward and reverse primers. Cycling conditions were as follows: $95^{\circ} \mathrm{C}$ for 10 minutes followed by 40 cycles of $95^{\circ} \mathrm{C}$ for 10 seconds and $60^{\circ} \mathrm{C}$ for 30 seconds, followed by a dissociation curve analysis from 60 to $95^{\circ} \mathrm{C}$. The primers sequence was 5'CCTGTGCACCAAGGTGCCGGAACT3' (forward) 5'CCACCCTGGTCTTGGATCCAGCCC3' (reverse) for Bax; 5'ATGGGGAAGGTGAAGGTCG3' (forward) and 5'GGGTCATTGATGGC AACAAT ATC3' (reverse) for GAPDH. The Bcl-2 transcription levels were measured by a TaqMan real-time quantitative PCR and analyzed as previously described. ${ }^{31}$ The following primers obtained from Applied Biosystems were used: GAPDH, Hs99999905_m1; Bcl-2, Hs00608023_ml.

Relative changes in gene expression between untreated (control) and treated cells were deter- 
mined using the $\Delta \Delta \mathrm{Ct}$ method. Levels of the target transcript were normalized to a GAPDH endogenous control that was constantly expressed in both groups $(\Delta \mathrm{Ct})$. For $\Delta \Delta \mathrm{Ct}$ values, additional subtractions were performed between treated and control $\Delta \mathrm{Ct}$ values. The final values reported in in Fig. 3C were expressed as fold of induction and were the average of the results obtained from duplicate experiments.

\section{F. Motility Assays}

HCT-116 cells were assayed for their migration activity using a modified Boyden chamber method. ${ }^{32}$ In brief, polycarbonate filters with an $8-\mu \mathrm{m}$ pore size were coated with $10 \mu \mathrm{g}$ calf-skin collagen $($ Calbiochem) $/ \mathrm{mL}$ acetic acid (0.1 M). Cells (2 $\times 10^{6} / \mathrm{mL}$ ) were suspended in serum-free McCoy's $5 \mathrm{~A}$ modified medium supplemented with $0.1 \%$ bovine serum albumin in the presence of increasing doses $(5,10,15$, and $20 \mu \mathrm{g} / \mathrm{mL})$ of either CWE-Pef or CWE-Pn (cells with DMSO were used as the control) and transferred into the upper wells. Fetal bovine serum $(10 \%)$ in culture medium was used as a chemoattractant in the lower chamber. After 22 hours of incubation at $37^{\circ} \mathrm{C}$, cells on the upper surface of the membrane were removed with a cotton swab and filters were fixed and stained with Dif-Quick solution (Medion Diagnostics $\mathrm{GmbH}$, Düdingen, Switzerland). The number of migrating cells were counted in 10 high-power fields per well at $400 \times$ magnification. The graphs in Fig. 4 report the percentage of migrating cells versus the control calculated with the following formula: (no. of migrating treated cells/no. of migrating control cells) $\times 100$. Each treatment dose was tested in at least 3 independent experiments.

\section{G. Cell Aggregation Assay}

Cell aggregation assays were performed essentially as described by Zhu et al. ${ }^{33}$ In brief, a single-cell suspension was obtained using a standard trypsinization procedure for cells treated for 18 hours with $20 \mu \mathrm{g} / \mathrm{mL}$ of either CWE-Pef or CWE-Pn and with DMSO as a control. A total of $2 \times 10^{5}$ cells in
$1 \mathrm{~mL}$ of serum-free McCoy's 5A modified medium were placed in polystyrene microtubes and were gently shaken for 1 hour at $37^{\circ} \mathrm{C}$. At the end, glutaraldehyde (at a final concentration of $2 \%[\mathrm{v} / \mathrm{v}]$ ) was added to stop the aggregation process. Homotypic aggregation was evaluated microscopically in a hemocytometer by counting only single, nonaggregating cells.

The percentage of aggregated cells was calculated as $(1-\mathrm{Ne} / \mathrm{Nc}) \times 100$, where $\mathrm{Ne}$ is the number of single cells after incubation at $37^{\circ} \mathrm{C}$ and $N c$ is the number of single cells before incubation (after the standard trypsinization procedure). The effect of treatment was evaluated by taking into account the average results obtained from at least 3 independent experiments.

\section{H. Adhesion Assay on the HUVEC Monolayer}

HUVECs grown to confluence in 24-well plates were fixed with glutaraldehyde $0.0125 \%$ (Agar Scientific Ltd., Stanted, Essex, UK). After fixation, cells were treated with $10 \mathrm{mM}$ ethanolamine to block aldehydic groups and washed several times before plating the cancer cells. HCT-116 cells previously treated for 18 hours with increasing doses $(1,5,10$, and $20 \mu \mathrm{g} / \mathrm{mL})$ of either CWEPef or CWE-Pn and with DMSO as a control were detached with trypsin, were resuspended in plain medium containing $0.5 \%$ bovine serum albumin at $35 \times 10^{4}$ cells $/ \mathrm{mL}$, and for 60 minutes were allowed to attach on the HUVEC monolayer. Each well was rinsed twice with phosphate-buffered saline to remove nonadherent cells; the attached cells were stained with hematoxylin and eosin. Each treatment dose was assayed at least in triplicate; 5 high-power $(400 \times)$ fields were counted for each well. We reported the percentage of adherent cells versus the control calculated with the following formula: (no. of adherent treated cells/no. of adherent control cells) $\times 100$ (Fig. 6A). The effect of each treatment dose was evaluated by taking into account the average results obtained from 3 independent experiments. 


\section{Western Blot Analysis}

Total cell lysates were subjected to sodium dodecyl sulphate polyacrylamide gel electrophoresis followed by Western blotting as previously described. ${ }^{31}$ In brief, HCT-116 cells after 18 hours of treatment with different concentrations $(10,20$, and $50 \mu \mathrm{g} / \mathrm{mL}$ ) of either CWE-Pef or CWE-Pn or with $0.001 \%$ DMSO (used as a control) were washed and lysed in lysis buffer $(150 \mathrm{mM}$ sodium chloride [NaCl], $2 \mathrm{mM}$ TrisHCl [pH 7.5], 1\% Triton, $1 \mathrm{mM}$ phenylmethylsulfonyl fluoride, $1 \mathrm{mM}$ EDTA, $1 \mathrm{mM}$ EGTA, $1 \mu \mathrm{g} / \mathrm{mL}$ leupeptin, $1 \mu \mathrm{g} / \mathrm{mL}$ aprotinin, $2 \mathrm{mM}$ sodium orthovanadate, $10 \mathrm{mM}$ sodium pryophosphate, $100 \mathrm{mM}$ sodium fluoride) on ice for 1 hour. The cell lysate was clarified via high-speed centrifugation for 15 minutes at $4{ }^{\circ} \mathrm{C}$, and an aliquot of the supernatant was assayed to determine the protein concentration using the Bradford method. ${ }^{34}$ Proteins were separated by $8 \%$ or $10 \%$ sodium dodecyl sulphate polyacrylamide gel electrophoresis and transferred to Hybond ECL nitrocellulose membrane (GE Healthcare Life Sciences). The membrane was incubated in block solution (5\% nonfat dry milk, $20 \mathrm{mM}$ Tris, $140 \mathrm{mM} \mathrm{NaCl}, 0.1 \%$ Tween-20), and probed overnight at room temperature with specific antibodies against phosphotyrosine, extracellular signal-regulated kinase (ERK) 1/2 and phospho-ERK 1/2 (Cell Signaling Technology, Danvers, MA), actin,${ }^{35}$ and E-cadherin (Cell Signaling Technology). After 3 washes with $20 \mathrm{mM}$ Tris, $140 \mathrm{mM} \mathrm{NaCl}$, and $0.1 \%$ Tween-20, the membrane was incubated with horseradish peroxidase-conjugated secondary antibodies for 1 hour at room temperature, and proteins were detected using the Super Signal enhanced chemiluminescence detection system (Pierce, Rockford, IL, USA). The results were confirmed by at least 3 independent experiments.

\section{J. Statistical Analysis}

Significant differences between treated and untreated HCT-116 cells were determined using the Student $t$ test, with a significance level set at $P<$ 0.05 .

\section{RESULTS AND DISCUSSION}

\section{A. Growth Inhibition of HCT-116 Cells by CWE-Pef and CWE-Pn}

Cancer cells are characterized by their uncontrolled growth resulting from the altered function of the genes that regulate cell proliferation. Thus, one of the main features required to propose a compound as an anticancer agent is its ability to inhibit the proliferation of cancer cells, thus leading to a reduction of the tumor mass.

To perform a preliminary screening of the antitumor activity of the CWE-Pef and CWE-Pn, we evaluated the proliferation rate of highly invasive colon cancer HCT-116 cells by means of a crystal violet assay. As shown in Fig. 1A, the treatment of cancer cells with increasing concentrations $(0-100$ $\mu \mathrm{g} / \mathrm{mL}$ ) of either CWE-Pef or CWE-Pn for 24 hours induced a statistically significant dose-dependent decrease of cell viability. Moreover, light microscopy also clearly showed that after 24 hours of treatment with CWE-Pef the HCT-116 cell monolayer was drastically altered in comparison to the untreated condition (Fig. 1B), and the same effect was observed following treatment with CWE-Pn (data not shown). The inhibitory effects on HCT116 proliferation was not caused by a nonspecific cytotoxic effect of CWE-Pef and CWE-Pn because both extracts did not have any significant effect on the proliferation of normal cells such as HUVECs (Fig. 2). Several data reported in literature widely show that natural compounds extracted from numerous mushrooms, including some species of the genus Pleurotus, are able to inhibit tumor cell proliferation. ${ }^{5,10,16-19}$ According to this evidence, our results suggest that cold-water extraction allowed bioactive compounds that suppress proliferation of colon cancer cells without significant effect on proliferation of normal cells to be isolated from both $P$. eryngii var. ferulae and $P$. nebrodensis. 

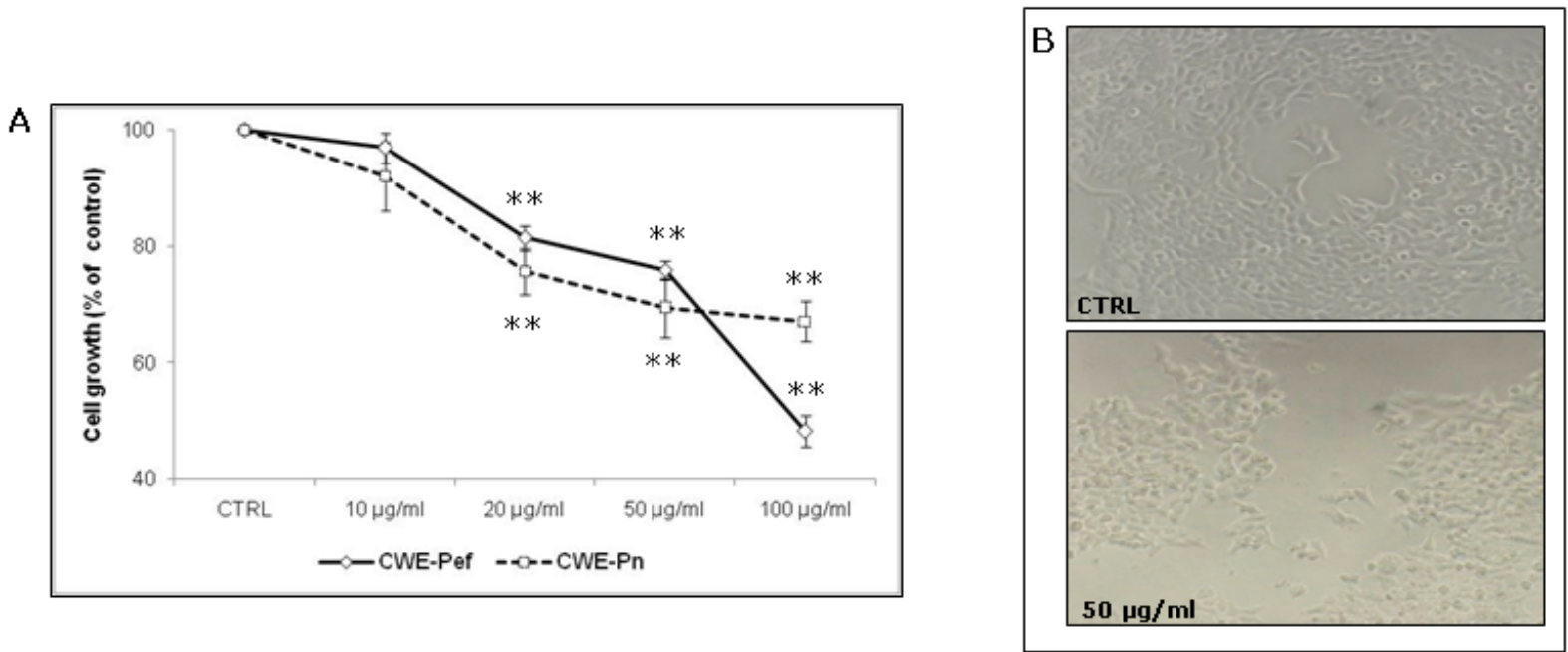

FIG. 1: The effects of cold-water extracts of Pleurotus eryngii var. ferulae (CWE-Pef) and Pleurotus nebrodensis (CWE-Pn) on the proliferation rate and morphology of colon cancer cells. A: HCT-116 cells were treated for 24 hours with increasing doses of mushroom extracts. Control cells (CTRL) were maintained in dimethyl sulfoxide $0.002 \%$ for the same amount of time. Proliferation was assessed after 24 hours, as described in Materials and Methods. Each bar represents the mean \pm standard deviation of at least 3 independent experiments. ${ }^{*}$ Significant difference $(P \leq$ 0.01 ) in comparison to the control. B: Representative phase-contrast micrographs of HCT116 cells treated for 24 hours with vehicle (CTRL) and $50 \mu \mathrm{g} / \mathrm{mL}$ CWE-Pef (200× magnification).

\section{B. CWE-Pef and CWE-Pn Induce Apoptosis in HCT-116 Cells}

An induction of apoptosis is considered a good strategy for cancer treatment. Therefore, in the areas of cancer chemoprevention and chemotherapy, many studies have been pursued with the aim of identifying mycochemicals of mushroom origin, as well as phytochemicals of plant origin, that show an ability to induce apoptosis in cancer cells. Thus, to determine whether the observed decrease in cell number after treatment with CWE-Pef and CWE-Pn was due to the induction of apoptosis, we performed an acridine orange/ethidium bromide double-staining assay. As reported in Fig. 3A, 18 hours of cell treatment with $20 \mu \mathrm{g} / \mathrm{mL}$ of CWE-Pef and CWE-Pn caused a significant increase in the percentage of apoptosis compared to the untreated cells, and this can be clearly seen in the representative micrographs in Fig. 3B.

To examine whether the expression of key proapoptotic and antiapoptotic genes could be modulated by CWE-Pef and CWE-Pn treatment, we tested messenger RNA (mRNA) expression levels of Bcl-2 and Bax in HCT-116 cells after 18 hours of treatment with $20 \mu \mathrm{g} / \mathrm{mL}$ of both extracts. Results indicated that the expression level of $\mathrm{Bcl}-2$ mRNA was significantly lower in both treatment conditions compared to the control, whereas the expression of Bax mRNA was significantly and markedly increased in cells treated with CWEPef compared to untreated cells, but no significant changes were found in HCT-116 cells treated with CWE-Pn (Fig. 3C). However, it is widely reported that it is not the increased or decreased expression of Bax or Bcl-2 alone, but rather the ratio of the 2 molecules that is important in determining a cell's susceptibility to apoptosis. For this reason, the ratio of $\mathrm{Bax}$ to $\mathrm{Bcl}-2$ at both the protein and mRNA level is typically used as an index of apoptosis. ${ }^{36-38}$ Thus, it was interesting to find that, despite the observed data at the individual mRNA expression level, treatment with both extracts caused a significant increase in the Bax:Bcl-2 mRNA ratio (Fig. 3D), confirming the ability of CWE-Pef and CWE-Pn to promote an apoptotic response in HCT-116 cells 


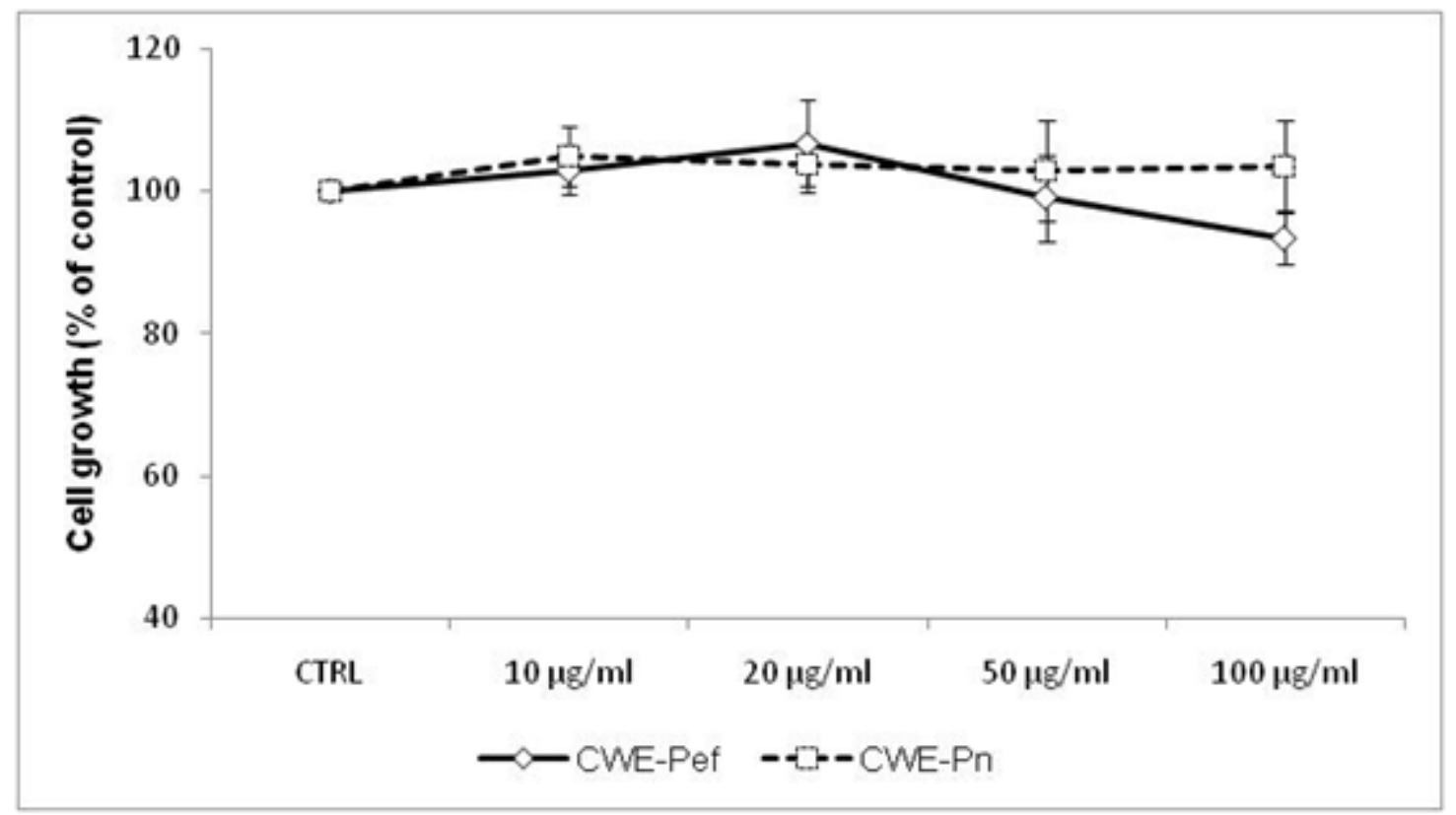

FIG. 2: The effects of cold-water extracts of Pleurotus eryngii var. ferulae (CWE-Pef) and Pleurotus nebrodensis (CWE-Pn) on the proliferation of human umbilical cord endothelial cells (HUVECs). HCT-116 HUVECs were treated for 24 hours with increasing doses of mushroom extracts. Control cells (CTRL) were maintained in dimethyl sulfoxide $0.002 \%$ for the same amount of time. Proliferation was assessed after 24 hours, as described in Materials and Methods. Each bar represents the mean \pm standard deviation of at least 3 independent experiments.

at the molecular level. Other studies have similarly demonstrated that compounds extracted from several species of mushrooms, such as Ganoderma lucidum (W.Curt.:Fr.) P. Karst., Poria cocos F.A. Wolf, Sarcodon scabrosus (Fr.) P. Karst., and Fomitopsis nigrescens (Bres.) Bondartsev \& Singer, are able to activate apoptosis in cancer cells by inducing an increase of the Bax:Bcl-2 ratio. ${ }^{39-41}$ Our findings provide the first evidence that both CWEPef and CWE-Pn contain compounds that are able to induce the apoptosis of colon cancer cells.

\section{Effect of CWE-Pef and CWE-Pn on the Migration, Adhesion, and Aggregation of Tumor Cells}

The reduction in cell-to-cell cohesion and the increase in cell migration are 2 closely interrelated cellular processes related to the acquisition of a transformed phenotype, and play an important role in tumor invasion and metastasis. ${ }^{42}$ Thus an inves- tigation of the ability of new natural compounds to inhibit the migration of cancer cells and to promote cell-cell adhesion is considered an aspect of particular relevance in order to establish their antitumor capabilities. As shown in Fig. 4, 18-hour treatment of HCT-116 cells with CWE-Pef and CWE-Pn decreased cell motility compared to untreated controls, even if with differing efficacy. We observed that the CWE-Pef treatment was able to inhibit HCT-116 cell motility in a dose-dependent manner from $30 \%( \pm 6 \%)$ with $10 \mu \mathrm{g} / \mathrm{mL}$ dose $(P$ $<0.05)$ to $55 \%( \pm 5 \%)$ with a $20 \mu \mathrm{g} / \mathrm{mL}$ dose $(P<$ $0.01)$. Otherwise, the CWE-Pn was able to induce a significant decrease in cell motility only at the dose of $20 \mu \mathrm{g} / \mathrm{mL}$ (about $40 \% \pm 3 \% ; P<0.05$ ). The ability of several mushroom compounds, such as those extracted from G. lucidum or Antrodia camphorata (M. Zang \& C. H. Su) Sheng H. Wu, Ryvarden \& T.T. Chang, to suppress the migration of tumor cells has already been described; an inhibitory activity of tumor invasion and metastasis 

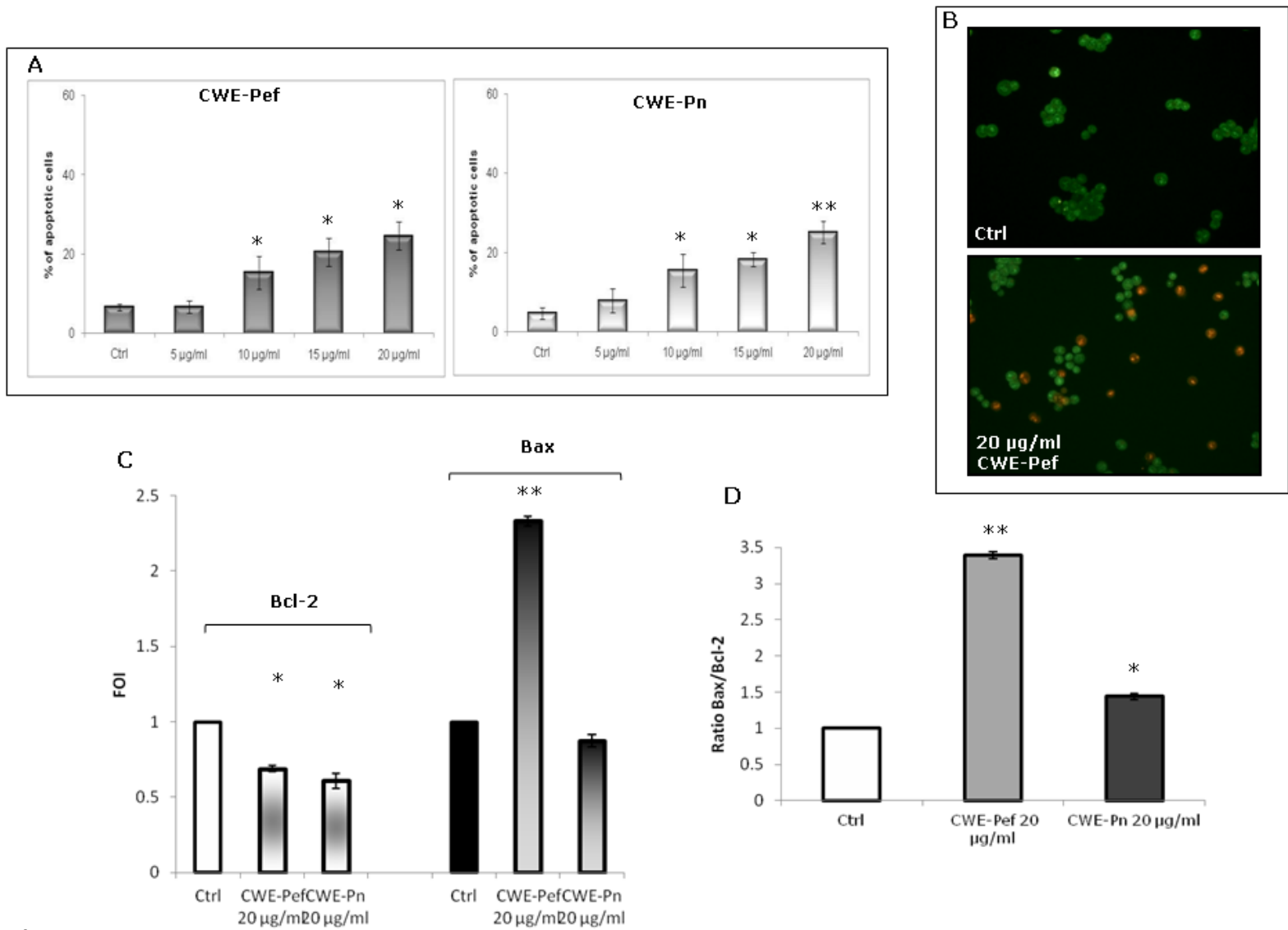
$20 \mu \mathrm{g} / \mathrm{mRO} \mu \mathrm{g} / \mathrm{ml}$

FIG. 3: The Effects of cold-water extracts of Pleurotus eryngii var. ferulae (CWE-Pef) and Pleurotus nebrodensis (CWE-Pn)on the induction of apoptosis in HCT-116 cells. A: Treatment with CWE-Pef and CWE-Pn for 18 hours induced an increase of apoptosis in the HCT-116 cells, as detected by acridine orange/ethidium bromide staining. At least 200 cells/field were counted in each experiment. The percentage of apoptotic cells was determined as described in Materials and Methods. Each value reported in the graph represents the mean \pm standard deviation of at least 3 independent experiments. Significant differences in comparison to the control: ${ }^{*} P \leq 0.05 ;{ }^{* *} P \leq 0.01$. B: Representative micrographs of HCT-116 cells stained with acridine orange/ethidium bromide after 18 hours of treatment with vehicle (CTRL) and $20 \mu \mathrm{g} / \mathrm{mL}$ CWE-Pef. Viable cells are green, whereas apoptotic cells show orange nuclei (200× magnification). Modulation of Bcl-2 and Bax messenger RNA expression levels (C) and Bax:Bcl-2 messenger RNA ratio (D) in HCT-116 cells treated for 18 hours with $20 \mu \mathrm{g} / \mathrm{mL}$ CWE-Pef and CWE-Pn. GAPDH was used as the control gene by following the procedure described in the Materials and Methods. Each value represents the mean \pm standard deviation of duplicate experiments. Significant difference in comparison to the control: ${ }^{*} P \leq 0.05$; ${ }^{* *} P \leq$ 0.01. FOI, fold of induction (see Materials and Methods).

has been reported. ${ }^{43,44}$

We also assessed whether treatment with CWE-Pef and CWE-Pn modulated cell-cell interaction by evaluating the ability of HCT-116 cells to form cell aggregates. Results, shown in Fig. 5A, indicated that the 2 extracts promoted spontaneous HCT-116 cell-cell aggregation. Compared to con- trol conditions, pretreatment for 18 hours with 20 $\mu \mathrm{g} / \mathrm{mL}$ CWE-Pef and CWE-Pn caused an increase in aggregated cells of $29 \%( \pm 1.2 \% ; P<0.05)$ and $22 \%( \pm 2.75 \% ; P<0.01)$, respectively.

It is well known that the reduced cell-cell adhesion characterizing epithelial cancer cells is closely associated with the loss of E-cadherin. In 

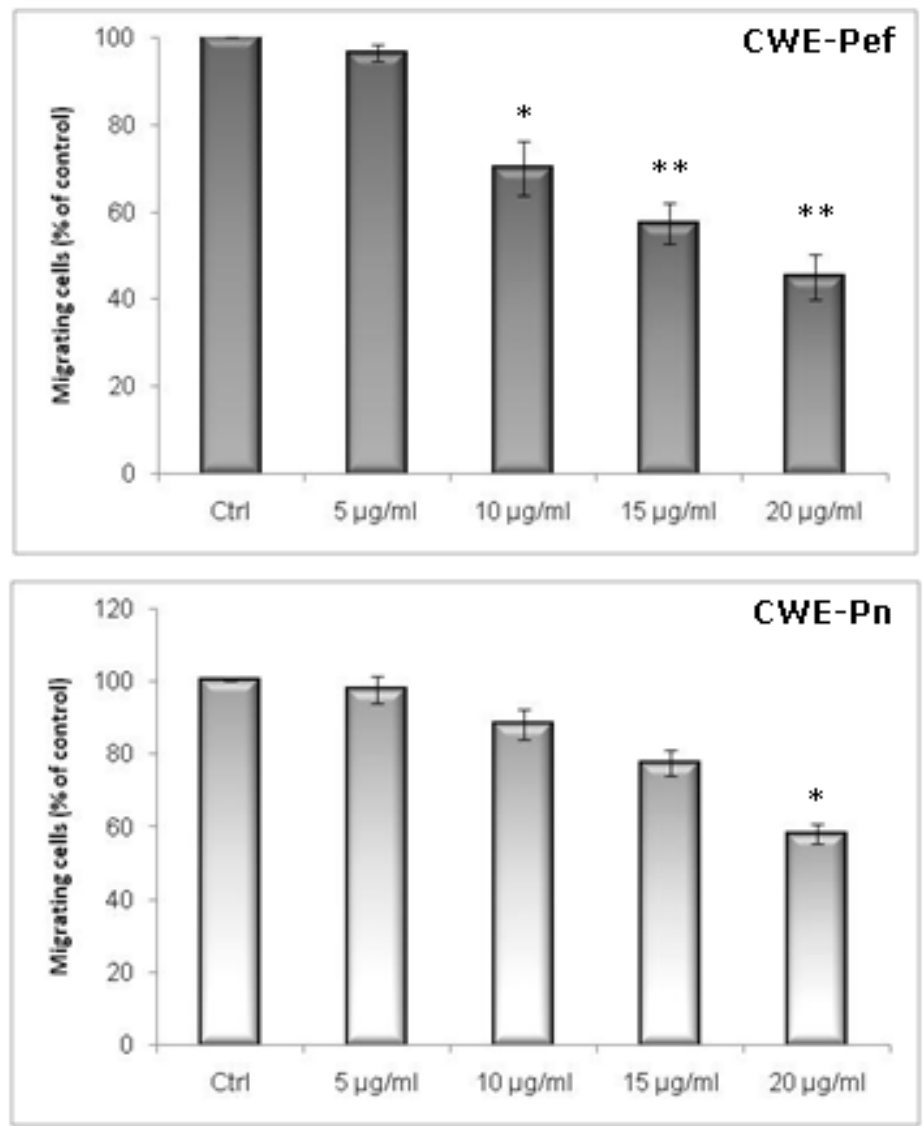

FIG. 4: Cold-water extracts of Pleurotus eryngii var. ferulae (CWE-Pef) and Pleurotus nebrodensis (CWE-Pn)inhibit the migration of HCT-116 cells. The effect of CWE-Pef and CWE-Pn on the migration of HCT-116 cells was evaluated by using a modified Boyden chamber, as described in the Materials and Methods. The histograms show the effects of CWE-Pef (top) and CWE-Pn treatment (bottom) on the percentage of migrating treated cells in comparison to the control (Ctrl). Each bar represents the mean \pm standard deviation of at least 3 independent experiments. Significant difference in comparison to the control: ${ }^{*} P \leq 0.05 ;{ }^{* *} P \leq 0.01$.

light of the positive effect induced by CWE-Pef and CWE-Pn on cell aggregation, we wanted to verify whether the 2 extracts might modulate the expression of E-cadherin. The results obtained by Western blot assay supported our hypothesis; it was evident that 18 hours of treatment with both extracts induced a net increase of E-cadherin expression in HCT-116 cells (Fig. 5B). This was a really attractive result because the increase of E-cadherin expression is considered a protective event that is able to inhibit tumor progression; for this reason, therapeutic approaches that aim to increase the expression of E-cadherin have been proposed for cancer treatment. ${ }^{45}$ Two recent independent works have reported data indicating that 2 triterpenes extracted from G. lucidum, ganoderic acid T and ganodermanontriol, are able to induce cell aggregation and the upregulation of E-cadherin in colon cancer cells. ${ }^{46,47}$ However, correlations among these 2 effects have never been described. In this study, we demonstrated that the ability of CWEPef and CWE-Pn to affect the cell-cell adhesion of HCT-116 cells is associated with an induction of E-cadherin expression.

Changes in the "adhesive migratory" phenotype acquired by tumor cells during the complex process of malignant transformation also cause cell migration into the host connective tissue, 
A

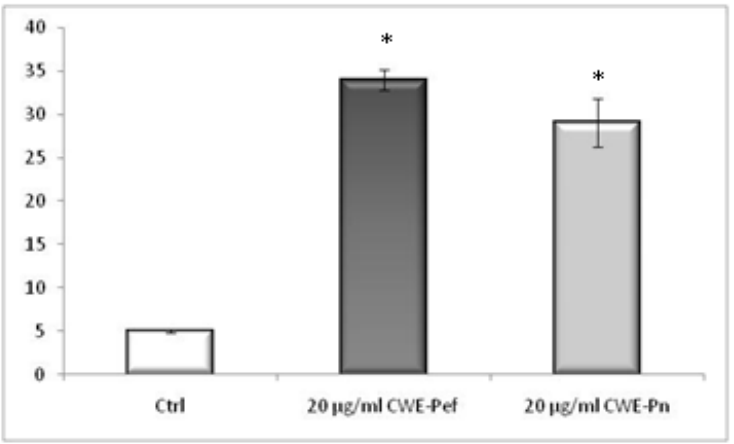

B
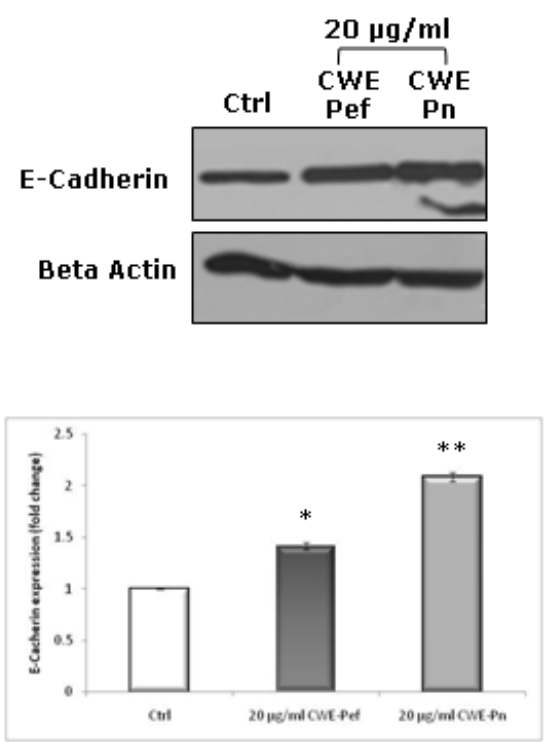

FIG. 5: Cold-water extracts of Pleurotus eryngii var. ferulae (CWE-Pef) and Pleurotus nebrodensis (CWE-Pn) enhance cell aggregation and E-cadherin expression. A: After pretreatment of HCT-116 cells for 18 hours with $20 \mu \mathrm{g} /$ $\mathrm{mL}$ of CWE-Pef and CWE-Pn, the percentage of aggregated cells was determined as described in the Materials and Methods. Values reported in each graph are the mean \pm standard deviation of at least 3 independent experiments. Ctrl, control. B, top: Western blot analysis of E-cadherin in HCT-116 cells treated for 18 hours with the indicated dose of CWE-Pef and CWE-Pn (upper panel); Western blot analysis of $\beta$-actin was performed to ensure equal loading (bottom panel). B, bottom: Densitogram corresponding to E-cadherin Western blot analysis is shown. The blot densities are expressed as folds of control. Data are mean \pm standard deviation $(n=3)$. Significant difference in comparison to the control: ${ }^{*} P \leq 0.05 ;{ }^{* *} P \leq 0.01$.

intravasation into the cancer-associated vasculature, and extravasation to distant organs. The intravasation of cancer cells is a process involving several steps, including their initial adhesion to endothelial cells. Thus, this phase represents a crucial starting point for the dissemination of cancer cells. Based on this consideration, we performed an adhesion assay to test whether the adhesion of HCT-116 cells to HUVECs was affected by treatment with CWE-Pef and CWE-Pn. As shown in Fig. 6A and B, both extracts were able to induce a negative modulation of adhesion of cancer cells and HUVECs after 18 hours of pretreatment, even if with different modalities. We observed that, compared to the control, the maximum inhibiting effect was already reached by CWE-Pef at a dose of $5 \mu \mathrm{g} / \mathrm{mL}$ (about $45 \% \pm 9 \%$;
$P<0.001$, whereas CWE-Pn induced a dose-dependent inhibition of the adhesion of cancer cells to the endothelial cells, with an inhibition of $70 \%$ $( \pm 6.8 \% ; P<0.001)$ when the maximum dose was used (Fig. 6A). The representative phase contrast micrographs in Fig. 6B show the decrease in adhesion of HCT-116 cells (dark spherical cells) to the HUVEC monolayer (visible as background) after 18 hours of pretreatment with $20 \mu \mathrm{g} / \mathrm{mL}$ CWE-Pef. Even if there is much data in the literature that shows angiogenic inhibitory activities of several mycochemicals, ${ }^{3}$ to our knowledge no evidence of the effects of mushroom compounds in regulating cancer cell-endothelial cell interaction has been reported.

Taken together, our results indicate that CWEPef and CWE-Pn inhibit HCT-116 cell motility, 

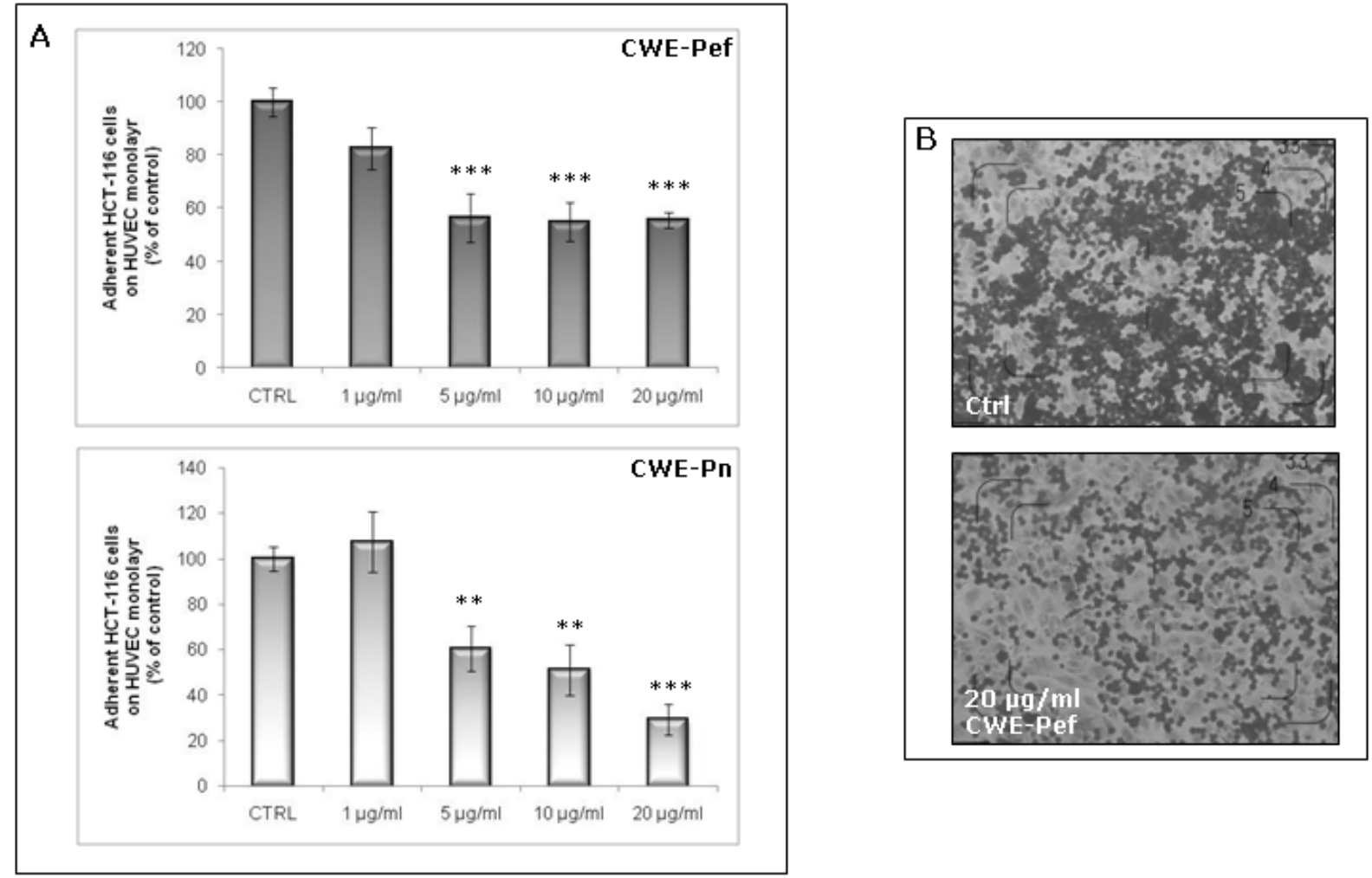

FIG. 6: Cold-water extracts of Pleurotus eryngii var. ferulae (CWE-Pef) and Pleurotus nebrodensis (CWE-Pn) inhibit the adhesion of HCT-116 cells to the human umbilical cord endothelial cell (HUVEC) monolayer. A: After pretreatment for 18 hours with increasing doses of CWE-Pef and CWE-Pn, the adhesion of HCT-116 cells to the HUVEC monolayer was determined as described in the Materials and Methods. The 2 histograms show the percentage of adherent HCT-116 cells treated with CWE-Pef (top) and CWE-Pn (bottom) in comparison to the control (CTRL). Each bar represents the mean \pm standard deviation of at least 3 independent experiments. Significant difference in comparison to the control: ${ }^{*} P \leq 0.05 ;{ }^{* *} P \leq 0.01$; ${ }^{* *} P \leq 0.001$. B: Representative phase-contrast micrographs show the adhesion of HCT116 cells (dark spherical cells) pretreated for 18 hours with dimethyl sulfoxide (Ctrl; top) and 20 $\mu \mathrm{g} / \mathrm{mL}$ CWE-Pef (bottom) on the HUVEC monolayer (visible as background).

preventing interactions with endothelial cells and enhancing cell-cell aggregation and thus supporting the hypothesis that these extracts can be used as new sources of alternative therapeutic agents for cancer treatment.

\section{Modulation of Cell Signal Pathways by CWE-Pef and CWE-Pn}

To investigate the biochemical basis of the effects of CWE-Pef and CWE-Pn on HCT-116 cells, we evaluated the ability of both extracts to modulate intracellular signal transduction pathways. Therefore, we analyzed the global phosphotyrosine signature and phosphorylation levels of ERK1/2, a key component of the Ras-mitogen-activated protein kinase pathway that regulates many critical cellular pathways involved in cell proliferation, apoptosis, migration, and differentiation. ${ }^{48,49}$

As shown in Fig. 7A, the treatment of HCT116 colon cancer cells with CWE-Pef and CWEPn inhibited tyrosine phosphorylation of different proteins compared to DMSO-treated cells (control). A stronger activity in the modulation of tyrosine phosphorylation levels of CWE-Pn compared to CWE-Pef also was observed. Protein tyrosine phosphorylation is a dynamic reversible posttranslational modification that plays a major 


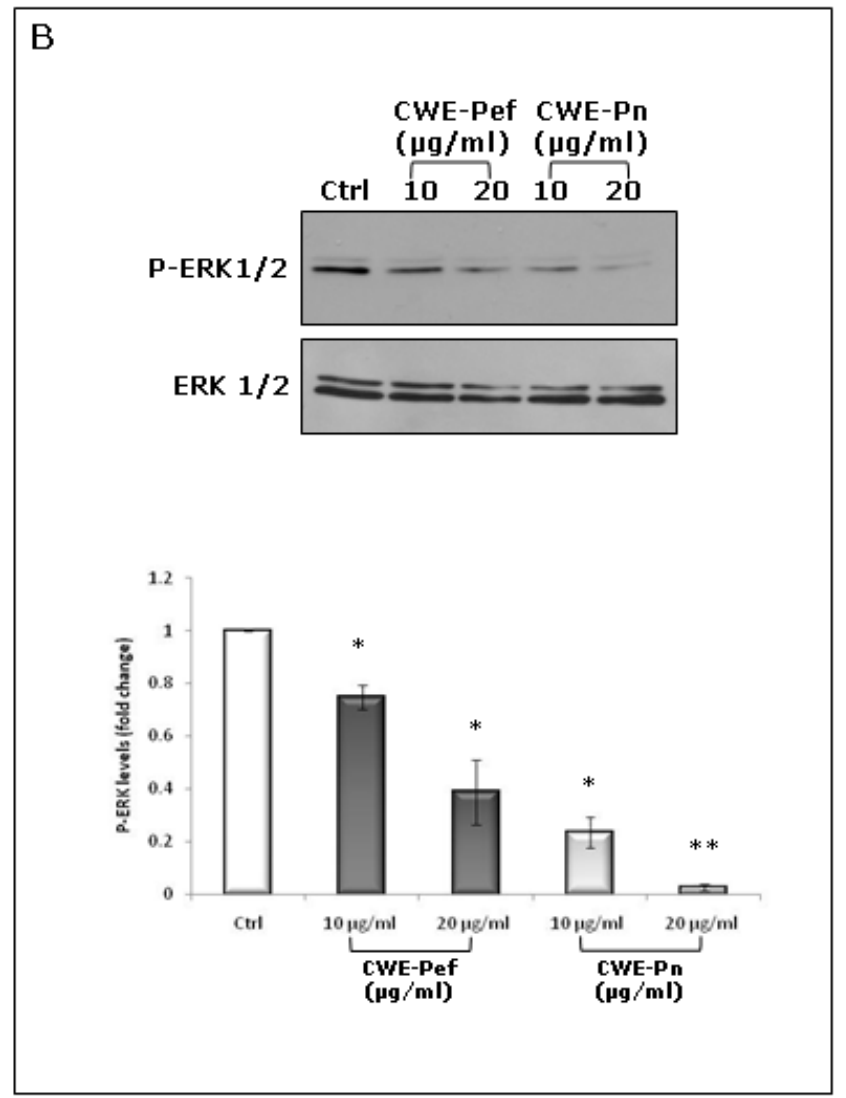

FIG. 7: The effects of treatment with cold-water extracts of Pleurotus eryngii var. ferulae (CWE-Pef) and Pleurotus nebrodensis (CWE-Pn) on intracellular signaling pathways. Whole-cell lysates were prepared from HCT-116 cells treated with 10 and $20 \mu \mathrm{g} / \mathrm{mL}$ CWE-Pef and CWE-Pn for 24 hours and subjected to Western blot analysis with antibodies against phosphorylated tyrosine proteins and $\beta$-actin to ensure equal loading $(\mathbf{A})$ or with phospho-extracellular signal-regulated kinase (ERK) $1 / 2$ and ERK 1/2 (B), as described in the Materials and Methods. B, bottom: Densitogram corresponding to Western blot analysis of phospho-ERK1/2 is shown. The blot densities are expressed as folds of control. Data are mean \pm standard deviation $(n=3)$. Significant difference in comparison to the control: ${ }^{*} P \leq 0.05 ;{ }^{* *} P \leq 0.01$.

role in cellular signalling. A balance between protein tyrosine kinases (PTKs) and protein tyrosine phosphatases controls the level of tyrosine phosphorylation. The deregulation of PTK and protein tyrosine phosphatase activity results in aberrant tyrosine phosphorylation, which has been associated with altered cell function, leading to malignant transformation. ${ }^{49,50} \mathrm{An}$ intense effort has been made to design and identify new PTK inhibitors for the development of new therapies. ${ }^{51}$ In light of these considerations, it was interesting to observe that the 2 mushrooms extract negatively modulated protein tyrosine phosphorylation. This ability to affect PTK signaling may be a newsworthy finding that supports the hypothesis of the antitumor activity of CWE-Pef and CWE- Pn.

Moreover, our results also showed that the phosphorylation of ERK1/2 was markedly inhibited in a dose-dependent manner by CWE-Pef and CWE-Pn treatment, with no remarkable changes in the total amount of ERK1/2 (Fig. 7B), indicating that treatment with both extracts was responsible for ERK1/2 inactivation. These data are in accord with other previous publications that showed the same effects of extracts from several species of mushrooms, such as Inonotus obliquus (Pers.:Fr.) 


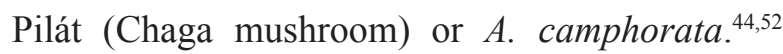
ERK1/2 are ubiquitously expressed kinases involved in the Ras-Raf-MEK-ERK signal transduction cascade. ${ }^{53}$ This pathway is distinctively upregulated in a variety of cancers, where it plays an important role in altering proliferation, antiapoptotic behavior, invasiveness, and neovascularization. ${ }^{54}$ Thus, it is reasonable to suppose that the antiproliferative and proapototic effects induced by CWE-Pef and CWE- Pn on HCT-116 may be related to their inhibitory effect on ERK1/2 phosphorylation.

\section{CONCLUSIONS}

Our data suggest that CWE-Pef and CWE- Pn have antitumoral properties linked to their ability to specifically inhibit the proliferation of colon cancer cells by inducing apoptosis, as demonstrated by the increased $B a x: B c l-2$ mRNA ratio, and to their capacity to affect cell migration, cell aggregation (by modulating E-cadherin expression), and the adhesion of tumor cells to endothelial cells. Moreover, we demonstrated that the treatment of HCT116 cells with CWE-Pef and CWE-Pn induced a negative modulation of intracellular signaling pathways specifically associated with the malignant phenotype. In conclusion, our study indicates that CWE-Pef and CWE- Pn can be considered new sources of efficient therapeutic agents for the treatment of cancer. However, further research is needed to more thoroughly explore and characterize their bioactive components.

\section{ACKNOWLEDGMENTS}

This work was supported by the Italian Association for Cancer Research (AIRC) to AR, the University of Palermo (International Cooperation) to FS; Ministry of University and Scientific Research (ex 60\%) to AR and FS. The authors also acknowledge financial support from the Italian Ministry of University and Research (MIUR) for a research fellowship awarded to GML and entitled "Biomorphological, ecological, productive and qualitative characterization of Pleurotus nebrodensis
(Inzenga) Quél. a rare Basidiomycetes at risk of extinction."

\section{REFERENCES}

1. Jemal A, Bray F, Center MM, Ferlay J, Ward E, Forman D. Global cancer statistics. CA Cancer J Clin. 2011;61(2):69-90.

2. Moehler M, Teufel A, Galle PR. New chemotherapeutic strategies in colorectal cancer. Recent Results Cancer Res. 2005;165:250-59.

3. Patel S, Goyal A. Recent developments in mushrooms as anti-cancer therapeutics: a review. 3 Biotech. 2012;2(1):1-15.

4. Sulkowska-Ziaja K, Muszynska B, Konska G. Biologically active compounds of fungal origin displaying antitumor activity. Acta Pol Pharm. 2005;62(2):153-59.

5. Wasser SP. Medicinal mushroom science: history, current status, future trends, and ansolved problems.Int J Med Mushrooms. 2010;12(1):1-16.

6. Chang Sh-T, Wasser SP. The role of culinary-mediicnal mushrooms on human welfare with a pyramid model for human health. Int J Med Mushrooms. 2012;14(2):95-134.

7. Yeung WH, Lu QL, Zhang Q, Go VLW. Chemical and biochemical basis of the potential anti-tumor properties of Ganoderma lucidum. Curr Top Nutraceut Res. 2004;2:67-77.

8. Cui J, Chisti Y. Polysaccharopeptides of Coriolus versicolor: physiological activity, uses, and production. Biotechnol Adv. 2003;21(2):109-22.

9. Ooi VE, Liu F. Immunomodulation and anti-cancer activity of polysaccharide-protein complexes. Curr Med Chem. 2000;7(7):715-29.

10. Chen JN, Ma CY, Tsai PF, Wang YT, Wu JS. In vitro antitumor and immunomodulatory effects of the protein PCP-3A from mushroom Pleurotus citrinopileatus. J Agric Food Chem. 2010;58:12117-22.

11. Maiti S, Bhutia SK, Mallick SK, Kumar A, Khadgi N, Maiti TK. Antiproliferative and immunostimulatory protein fraction from edible mushrooms. Environ Toxicol Pharmacol. 2008;26(2):187-91.

12. Xu X, Yan H, Chen J, Zhang X. Bioactive proteins from mushrooms. Biotechnol Adv. 2011;29(6):667-74.

13. Kimura Y, Taniguchi M, Baba K. Antitumor and antimetastatic effects on liver of triterpenoid fractions of Ganoderma lucidum: mechanism of action and isolation of an active substance. Anticancer Res. 2002;22(6A):3309-18.

14. Lin SB, Li CH, Lee SS, Kan LS. Triterpene-enriched extracts from Ganoderma lucidum inhibit growth of hepatoma cells via suppressing protein kinase $\mathrm{C}$, activating mitogen-activated protein kinases and G2-phase cell cycle arrest. Life Sci. 2003;72:2381-90.

15. Yang HL. Ganoderic acid produced from submerged culture of Ganoderma lucidum induces cell cycle arrest and 
cytotoxicity in human hepatoma cell line BEL7402. Biotechnol Lett. 2005;27(12):835-38.

16. Zaidman BZ, Yassin M, Mahajna J, Wasser SP. Medicinal mushroom modulators of molecular targets as cancer therapeutics. Appl Microbiol Biotechnol. 2005;67(4):453-68.

17. Sarangi I, Ghosh D, Bhutia SK, Mallick SK, Maiti TK. Anti-tumor and immunomodulating effects of Pleurotus ostreatus mycelia-derived proteoglycans. Int Immunopharmacol. 2006;6(8):1287-97.

18. Gu YH, Sivam G. Cytotoxic effect of oyster mushroom Pleurotus ostreatus on human androgen-independent prostate cancer PC-3 cells. J Med Food. 2006;9(2):196204.

19. Jedinak A, Sliva D. Pleurotus ostreatus inhibits proliferation of human breast and colon cancer cells through p53-dependent as well as p53-independent pathway. Int J Oncol. 2008;33(6):1307-13.

20. Lavi I, Friesem D, Geresh S, Hadar Y, Schwartz B. An aqueous polysaccharide extract from the edible mushroom Pleurotus ostreatus induces anti-proliferative and pro-apoptotic effects on HT-29 colon cancer cells. Cancer Lett. 2006;244(1):61-70.

21. Sun Y, Liu J. Purification, structure and immunobiological activity of a water-soluble polysaccharide from the fruiting body of Pleurotus ostreatus. Bioresour Technol. 2009;100(2):983-86.

22. Xu T, Beelman RB, Lambert JD. The cancer preventive effects of edible mushrooms. Anticancer Agents Med Chem. 2012;12(10):1255-63.

23. Wu JY, Chen CH, Chang WH, Chung KT, Liu YW, Lu FJ. Anti-cancer effects of protein extracts from Calvatia lilacina, Pleurotus ostreatus and Volvariella volvacea. Evid Based Complement Alternat Med. 2011;2011:982368.

24. Gargano ML, Saitta A, Zervakis GI, Venturella G. Building the jigsaw puzzle of the critically endangered Pleurotus nebrodensis: historical collection sites and an emended description. Mycotaxon. 2011;115:107-14.

25. Zervakis GI, Venturella G, Papadopoulou K. Genetic polymorphism and taxonomic infrastructure of the Pleurotus eryngii species-complex as determined by RAPD analysis, isozyme profiles and ecomorphological characters. Microbiology. 2001;147(Pt 11):3183-94.

26. La Guardia M, Venturella G, Venturella F. On the chemical composition and nutritional value of pleurotus taxa growing on umbelliferous plants (Apiaceae). J Agric Food Chem. 2005;53(15):5997-6002.

27. Venturella G, Ferri F. Progetto FUNGIS. Progetto di sviluppo per la funghicoltura in Sicilia. Programma Operativo Plurifondo 1994/99 - Misura 10.4 - Ricerca Applicata, indagini e sperimentazione di interesse regionale Palermo. 2001:pp 118 (con CD ROM allegato).

28. Alessandro R, Flugy A, Russo D, Stassi G, De Leo A, Corrado C, Alaimo G, De Leo G. Identification and phenotypic characterization of a subpopulation of T84 hu- man colon cancer cells, after selection on activated endothelial cells. J Cell Physiol. 2005;203(1):261-72.

29. Saydam G, Aydin HH, Sahin F, Selvi N, Oktem G, Terzioglu E, Buyukkececi F, Omay SB. Involvement of protein phosphatase $2 \mathrm{~A}$ in interferon-alpha-2b-induced apoptosis in K562 human chronic myelogenous leukaemia cells. Leuk Res. 2003;27(8):709-17.

30. McGahon AJ, Martin SJ, Bissonnette RP, Mahboubi A, Shi Y, Mogil RJ, Nishioka WK, Green DR. The end of the (cell) line: methods for the study of apoptosis in vitro. Methods Cell Biol. 1995;46:153-85.

31. Alessandro R, Fontana S, Giordano M, Corrado C, Colomba P, Flugy AM, Santoro A, Kohn EC, De Leo G. Effects of carboxyamidotriazole on in vitro models of imatinib-resistant chronic myeloid leukemia. J Cell Physiol. 2008;215:111-21.

32. Albini A, Iwamoto Y, Kleinman HK, Martin GR, Aaronson SA, Kozlowski JM, McEwan RN. A rapid in vitro assay for quantitating the invasive potential of tumor cells. Cancer Res. 1987;47(12):3239-45.

33. Zhu Z, Sanchez-Sweatman O, Huang X, Wiltrout R, Khokha R, Zhao Q, Gorelik E. Anoikis and metastatic potential of cloudman S91 melanoma cells. Cancer Res. 2001;61(4):1707-16.

34. Bradford MM. A rapid and sensitive method for the quantitation of microgram quantities of protein utilizing the principle of protein-dye binding. Anal Biochem. 1976;72:248-54.

35. Alessandro R, Gallo A, Barranca M, Principe S, Taverna S, Duro G, Cassata G, Becchi M, Fontana S, De Leo G. Production of an egg yolk antibody against Parietaria judaica 2 allergen. Poult Sci. 2009;88(8):1773-78.

36. Chen J, Chu Y, Cao J, Yang Z, Guo X, Wang Z. T-2 toxin induces apoptosis, and selenium partly blocks, $\mathrm{T}-2$ toxin induced apoptosis in chondrocytes through modulation of the Bax/Bcl-2 ratio. Food Chem Toxicol. 2006;44(4):567-73.

37. Ghobrial IM, Witzig TE, Adjei AA. Targeting apoptosis pathways in cancer therapy. CA Cancer J Clin. 2005;55(3):178-94.

38. Mirjolet JF, Barberi-Heyob M, Didelot C, Peyrat JP, Abecassis J, Millon R, Merlin JL. Bcl-2/Bax protein ratio predicts 5-fluorouracil sensitivity independently of p53 status. Br J Cancer. 2000;83(10):1380-86.

39. Jiang J, Slivova V, Valachovicova T, Harvey K, Sliva D. Ganoderma lucidum inhibits proliferation and induces apoptosis in human prostate cancer cells PC-3. Int J Oncol. 2004;24(5):1093-99.

40. Zhang M, Chiu LC, Cheung PC, Ooi VE. Growth-inhibitory effects of a beta-glucan from the mycelium of Poria cocos on human breast carcinoma MCF-7 cells: cell-cycle arrest and apoptosis induction. Oncol Rep. 2006;15(3):637-43.

41. Dong M, Chen SP, Kita K, Ichimura Y, Guo WZ, Lu S, Sugaya S, Hiwasa T, Takiguchi M, Mori N, Kashima 
A, Morimura K, Hirota M, Suzuki N. Anti-proliferative and apoptosis-inducible activity of Sarcodonin G from Sarcodon scabrosus in HeLa cells. Int J Oncol. 2009;34(1):201-7.

42. Geiger T, Geiger B. Towards elucidation of functional molecular signatures of the adhesive-migratory phenotype of malignant cells. Semin Cancer Biol. 2010;20(3):146-52.

43. Chen NH, Zhong JJ. p53 is important for the anti-invasion of ganoderic acid $\mathrm{T}$ in human carcinoma cells. Phytomedicine. 2011;18(8-9):719-25.

44. Yang HL, Kuo YH, Tsai CT, Huang YT, Chen SC, Chang HW, Lin E, Lin WH, Hseu YC. Anti-metastatic activities of Antrodia camphorata against human breast cancer cells mediated through suppression of the MAPK signaling pathway. Food Chem Toxicol. 2011;49(1):290-98.

45. Buda A, Pignatelli M. E-cadherin and the cytoskeletal network in colorectal cancer development and metastasis. Cell Commun Adhes. 2011;18(6):133-43.

46. Jedinak A, Thyagarajan-Sahu A, Jiang J, Sliva D. Ganodermanontriol, a lanostanoid triterpene from Ganoderma lucidum, suppresses growth of colon cancer cells through ss-catenin signaling. Int J Oncol. 2011;38(3):761-67.

47. Chen NH, Liu JW, Zhong JJ. Ganoderic acid T inhibits tumor invasion in vitro and in vivo through inhibition of
MMP expression. Pharmacol Rep. 2010;62(1):150-63.

48. Roskoski R Jr. ERK1/2 MAP kinases: structure, function, and regulation. Pharmacol Res. 2012;66(2):105-43.

49. Blume-Jensen P, Hunter T. Oncogenic kinase signalling. Nature. 2001;411(6835):355-65.

50. Rush J, Moritz A, Lee KA, Guo A, Goss VL, Spek EJ, Zhang H, Zha XM, Polakiewicz RD, Comb MJ. Immunoaffinity profiling of tyrosine phosphorylation in cancer cells. Nat Biotechnol. 2005;23(1):94-101.

51. Ventura JJ, Nebreda AR. Protein kinases and phosphatases as therapeutic targets in cancer. Clin Transl Oncol. 2006;8(3):153-60.

52. Park JR, Park JS, Jo EH, Hwang JW, Kim SJ, Ra JC, Aruoma OI, Lee YS, Kang KS. Reversal of the TPAinduced inhibition of gap junctional intercellular communication by Chaga mushroom (Inonotus obliquus) extracts: effects on MAP kinases. Biofactors. 2006;27(14):147-55.

53. Wortzel I, Seger R. The ERK Cascade: distinct functions within various subcellular organelles. Genes Cancer. 2011;2(3):195-209.

54. Sebolt-Leopold JS. Advances in the development of cancer therapeutics directed against the RAS-mitogenactivated protein kinase pathway. Clin Cancer Res. 2008;14(12):3651-56. 
